\title{
Analysis of Preterm Induction of Labour
}

\author{
Kritika Agrawal ${ }^{1}$, Shubhangi Mande ${ }^{2}$, Lakshmi Rachakonda ${ }^{3}$ \\ ${ }^{1}$ Junior Resident, ${ }^{2}$ Professor and HOU, ${ }^{3}$ Professor and HOD, Department of OBGY MGM Medical College and Research Centre, \\ Aurangabad, Maharashtra, INDIA.
}

\begin{abstract}
:-
$>$ Background:

Worldwide $20-30 \%$ of labour cases are induced. We conducted an analysis to evaluate the success of labour induction for indicated preterm birth

\section{Material and Methods:}

A prospective observational study was conducted among 50 patients admitted in the Department of OBGY, MGM Medical College and Hospital, Aurangabad from 1st March 2019 to 31st March 2020.
\end{abstract}

\section{$>$ Results:}

There was a total of 50 deliveries during this period. The preterm induction majorly includes 20-34 years as this is the commonest reproductive age group seen in our hospital. More number of Hindus underwent induction. Multigravida requires induction more as compared to primigravida. More number of patients were induced between 32-36 weeks, reason being PPROM, severe preeclampsia, IUD and severe FGR. Vaginal delivery is more likely irrespective of bishop score.

\section{$>$ Conclusion:}

Induction of labour remains relevant obstetrics procedure and its outcome will depend on proper choice of patients and close intrapartum monitoring.

Keywords:- Induction of Labour, Preterm, Prematurity.

\section{INTRODUCTION}

Induction of labour is an obstetric intervention, when the process of labour is to be initiated using iatrogenic means for the purpose of maternal and/or fetal benefit. [1] The WHO mandates that inductions are to be performed with clear medical indications and when expected benefits outweigh the potential harm. Unpublished data from the WHO Global Survey on Maternal and Perinatal Health, covered 373 health-care facilities in 24 countries and over 300000 deliveries showed that $9.6 \%$ of the deliveries involved labour induction. [2] Indications in preterm pregnancy include pregnancy induced hypertension, uncontrolled diabetes, abruption placenta, premature rupture of membranes, intrauterine fetal growth restrictions, intrauterine fetal death, oligohydramnios. [3] There are various methods of induction, mechanical and pharmacological methods. Mifepristone, sweeping of membranes, foley's catheter with PGE2 gel, only PGE2 gel are few methods of induction. ${ }^{[4]}$
Misoprostol, prostaglandin E1 is less expensive, more stable and easier to store than PGE2. Its use may decrease the need for oxytocin induction and reduce the induction-todelivery intervals (Sanchez-Ramos and colleagues in 1997). [5]

Reviewed Cochrane data base support these recommendation, but caution that rates of uterine hyperstimulation with adverse fetal heart rate changes are increased with its use leading to increased caesarean rates. It can also significantly increase uterine tachysystole, meconium passage, and meconium aspiration compared with PGE2 gel (Wing and co-workers, 1995a). ${ }^{[6]}$

Next inducing agent is Prostaglandin E2 gel that increases the collagenase and hyaluronidase levels in the cervix and increase the submucosal water content that lead to softening of the cervix. It can also cause uterine hyperstimulation. Systemic effects include fever, vomiting and diarrhoea. ${ }^{[7]}$

In this study, we are analysing the methods and outcome of preterm induction of labor.
$>$ Aim of labour
To analyse method and outcome of preterm induction

\section{$>$ Objectives}
1. To make early diagnosis for need of induction
2. To select proper method of induction
3. To study maternal and neonatal morbidity and mortality for preterm delivery in indicated patients

\section{MATERIALS AND METHODS}

Study design: Prospective observational study

Study period: $1^{\text {st }}$ March 2019 to $31^{\text {st }}$ March 2019

Place of study: Department of OBGY, MGM Medical College and Hospital, Aurangabad.

All patients admitted in antenatal ward and labour room requiring preterm induction were included in this study. A detailed performa was made and details filled out. All patients were monitored in labour room with auscultation and NST. Mifepristone was given orally and PGE2 gel was inserted in posterior fornix. 


\section{RESULTS}

There was a total of 50 deliveries during this period. The preterm induction majorly includes 20-34 years as this is the commonest reproductive age group seen in our hospital. More number of Hindus underwent induction. Multigravida requires induction more as compared to primigravida. More number of patients were induced between 32-36 weeks, reason being PPROM, severe preeclampsia, IUD and severe FGR.

\begin{tabular}{|c|c|}
\hline AGE (years) & $\begin{array}{c}\text { NUMBER }(\%) \\
n=50\end{array}$ \\
\hline$<19$ & $03(6)$ \\
\hline $20-34$ & $45(90)$ \\
\hline$>34$ & $02(4)$ \\
\hline RELIGION & $\begin{array}{c}\text { NUMBER }(\%) \\
n=50\end{array}$ \\
\hline Hindu & $36(72)$ \\
\hline Muslim & $14(28)$ \\
\hline OCCUPATION & $\begin{array}{c}\text { NUMBER }(\%) \\
n=50\end{array}$ \\
\hline Working & 09 (18) \\
\hline Non-working & $41(82)$ \\
\hline LITERACY & $\begin{array}{c}\text { NUMBER }(\%) \\
n=50\end{array}$ \\
\hline Literate & $45(90)$ \\
\hline Illiterate & 05 (10) \\
\hline GRAVIDA & $\begin{array}{c}\text { NUMBER }(\%) \\
n=50\end{array}$ \\
\hline Primigravida & $22(44)$ \\
\hline Multigravida & $26(52)$ \\
\hline Grandmultipara & $02(4)$ \\
\hline
\end{tabular}

Table 1:- Maternal Demographics profile

Table 1 shows maximum patients in reproductive age group 20-34 years. There is maximum awareness in literate patients. Preterm induction more common in multigravida.

\begin{tabular}{|c|c|}
\hline GESTATIONAL AGE & $\begin{array}{c}\text { NUMBER (\%) } \\
\mathbf{n = 5 0}\end{array}$ \\
\hline$<27$ weeks & $05(10)$ \\
\hline $27-32$ weeks & $14(28)$ \\
\hline $32-36$ weeks & $31(62)$ \\
\hline
\end{tabular}

Table 2:- Early induction required for maternal indication.
ISSN No:-2456-2165

\begin{tabular}{|c|c|}
\hline INDICATIONS & $\begin{array}{c}\text { NUMBER (\%) } \\
\mathbf{n = 5 0}\end{array}$ \\
\hline PPROM & $18(36)$ \\
\hline Fetal demise & $14(28)$ \\
\hline Severe pre-eclampsia & $02(04)$ \\
\hline Severe preeclampsia + FGR & $03(06)$ \\
\hline $\begin{array}{c}\text { Severe preeclampsia + fetal } \\
\text { demise }\end{array}$ & $01(02)$ \\
\hline Oligohydramnios +FGR & $04(08)$ \\
\hline $\begin{array}{c}\text { Severe FGR with Doppler } \\
\text { changes }\end{array}$ & $02(04)$ \\
\hline Imminent eclampsia & $03(06)$ \\
\hline $\begin{array}{c}\text { Prolonged latent phase of } \\
\text { labour }\end{array}$ & $02(04)$ \\
\hline Hepatocellular carcinoma & $01(02)$ \\
\hline
\end{tabular}

Table 3:- Indications for induction

Though PPROM is commonest cause of preterm induction, majority of patients needed early induction for fetal indication also.

\begin{tabular}{|c|c|c|}
\hline \multirow{2}{*}{ METHOD } & \multicolumn{2}{|c|}{ OUTCOME (n=50) } \\
\cline { 2 - 3 } & VAGINAL & LSCS \\
\hline $\begin{array}{c}\text { PGE2 Gel } \\
\text { Intracervical Foley's with } \\
\text { gel }\end{array}$ & $09(18 \%)$ & 0 \\
\hline Mifepristone & $05(10 \%)$ & 0 \\
\hline Mifepristone-Misoprostol & $07(14 \%)$ & 0 \\
\hline TOTAL & $\mathbf{4 8}(\mathbf{9 6 \%})$ & $\mathbf{0 2}(\mathbf{4 \%})$ \\
\hline
\end{tabular}

Table 4:- Method of Induction and mode of delivery

Out of 50 patients, 2 underwent LSCS i/v/o fetal distress and another one i/v/o prolonged PPROM not willing for further vaginal trial. There were 15 fetal demise out of which 5 patients delivered by Mifepristone itself though they were planned for mifepristone followed by misoprostol initially.7 were induced via Mifepristone followed by Misoprostol and the rest 3 by PGE2 gel.

\begin{tabular}{|c|c|c|c|c|}
\hline \multirow{2}{*}{$\begin{array}{c}\text { BISHOP } \\
\text { SCORE }\end{array}$} & \multicolumn{2}{|c|}{ NUMBER OF PGE2 GEL (n=38) } & \multirow{2}{*}{ TOTAL } \\
\cline { 2 - 4 } & $\mathbf{1}$ & $\mathbf{2}$ & $\mathbf{3}$ & \\
\hline$<6$ & 01 & 11 & 13 & \\
& $(2.63 \%)$ & $(28.95 \%)$ & $(34.2 \%)$ & $\mathbf{2 5}$ \\
& 05 & 06 & 02 & $\mathbf{1 3}$ \\
& $(13.15 \%)$ & $(15.8 \%)$ & $(5.27 \%)$ & $\mathbf{( 3 4 . 2 \% )}$ \\
\hline TOTAL & $\mathbf{0 6}$ & $\mathbf{1 7}$ & $\mathbf{1 5}$ & $\mathbf{3 8}$ \\
& $(\mathbf{1 5 . 7 8 \% )}$ & $\mathbf{( 4 4 . 7 5 \% )}$ & $\mathbf{( 3 9 . 4 7 \% )}$ & \\
\hline
\end{tabular}

Table 5:- Distribution of Bishop Score 

$<6$.

More number of gels were required with bishop score

\begin{tabular}{|c|c|}
\hline TIME (in hours) & $\begin{array}{c}\text { NUMBER (\%) } \\
\mathbf{n = 3 8}\end{array}$ \\
\hline$<10$ & 03 \\
\hline $10-20$ & 13 \\
\hline $21-30$ & 10 \\
\hline$>31$ & 12 \\
\hline
\end{tabular}

Table 6:- Induction delivery time

In 12 patients induction to delivery time was $>31$ hours, out of which 6 patients labour was augmented with oxytocin.

\begin{tabular}{|c|c|c|c|c|}
\hline \multirow{2}{*}{$\begin{array}{c}\text { BABY } \\
\text { WEIGHT }\end{array}$} & \multicolumn{4}{|c|}{ OUTCOME (n=51) } \\
\cline { 2 - 5 } & IUD & $\begin{array}{c}\text { FRESH } \\
\text { STILL } \\
\text { BIRTH }\end{array}$ & NICU & $\begin{array}{c}\text { WITH } \\
\text { MOTHER }\end{array}$ \\
\hline $550 \mathrm{~g}-1.5 \mathrm{~kg}$ & $\begin{array}{c}13 \\
(25.5 \%)\end{array}$ & $\begin{array}{c}05 \\
(9.8 \%)\end{array}$ & $\begin{array}{c}08 \\
(15.7 \%)\end{array}$ & 0 \\
\hline $1.6 \mathrm{~kg}-2.5 \mathrm{~kg}$ & 02 & 0 & 09 & $07(13.7 \%)$ \\
& $(3.9 \%)$ & $(17.6 \%)$ & $05(9.8 \%)$ \\
\hline $2.5 \mathrm{~kg}$ & 0 & 0 & $\begin{array}{c}02 \\
(3.9 \%)\end{array}$ & $\mathbf{1 2}$ \\
\hline TOTAL & $\mathbf{1 5}$ & $\begin{array}{c}\mathbf{0 5} \\
(\mathbf{9 . 8} \%)\end{array}$ & $\begin{array}{c}\mathbf{1 3 7 . 2 \%} \\
(\mathbf{2 9 . 4 \% )}\end{array}$ & $\mathbf{( 2 3 . 5 \% )}$ \\
\hline
\end{tabular}

Table 7:- Neonatal Outcome

Majority of babies went to NICU in view of low birth weight and maturity. There was one twin delivery amounting to 51 neonates.

\begin{tabular}{|c|c|}
\hline COMPLICATIONS & $\begin{array}{c}\text { NUMBER (\%) } \\
\mathbf{n = 5 0}\end{array}$ \\
\hline YES & Atonic PPH $-02(04)$ \\
\hline NO & Traumatic PPH $-01(02)$ \\
\hline & $47(94)$ \\
\hline
\end{tabular}

Table 8:- Complications of PPH

Table 6 shows $94 \%$ did not have any complication while $6 \%$ of them had PPH

\section{DISCUSSION}

Labor is induced when delivery is likely to benefit the health of the fetus or mother or both. The induction is justified when the benefits to either mother or fetus outweigh those of continuing the pregnancy.

In our study, a total of 50 women who underwent induction of labor for a variety of indications were included in the study group. Maximum numbers of patients were in the age group between 20-34 years (45\%) and minimum age of patient was $<19$ years and $<34$ years.
According to Londero AP et al global aging of population with an increasing prevalence of women aged between 20 and 35 years, the change in social customs with a rise of second marriages, improvements to women's educational and professional outlooks as well as the diffusion of contraception. ${ }^{[8]}$

In our study, primigravida was $44 \%$, mutigravida $52 \%$ and Grandmultipara was 4\%. Our results showing that increases in Multigravida patients group are similar to the results of Nichols MR, et.al. [9] Despite the fact that multigravida women have had a previous pregnancy experience, the current study findings suggest that multigravida women may face more challenges than their primigravida counterparts as they adjust to becoming a mother of a second child. These differences highlight the implication that both groups require unique and possibly more specific support and resources. The multigravida mothers in this study had significantly lower maternal-fetal attachment scores than the primigravid mothers. This difference with their primigravid counterparts may indicate the possibility of less focus on the current pregnancy and on their unborn child and perhaps more attention to their other child. It has been suggested that multigravid women experience more fatigue and sleep problems and decreased functional status. ${ }^{[10]}$

Whereas, 31\% had 32-36 weeks of gestational age and least were $<27$ weeks. Similar, study also supported by Unger $\mathrm{H}$ et al about gestational age group. ${ }^{[11]}$ Gestational age in India is almost invariably confirmed by using earlyfirst-trimester ultrasound scanning, high survival rates are unlikely to reflect an inappropriate attribution of a more mature gestational age. Additionally, our data consistently reveal that early-term birth is associated with poorer survival, health, educational, and social outcomes. Our study also highlights the persistent association between gestations 32-36 weeks and an increased rate of hospital readmissions. The additional impact of environmentally modifiable factors (such as adequacy of housing stock) on those born preterm needs investigation. Targeted health and social policies may have a role to play in reducing the preterm-associated health disparity. ${ }^{[12]}$

In the present study, the highest success rate in the various groups was obtained whose patients had IUFD and subsequent cervical ripening and induction of labour, with vaginal delivery obtained in patients. Those who had prolonged pre labor rupture of Membranes (PROM) and subsequent oxytocin infusion followed this. This could have been so because of physiological mechanisms of labour were already probably being initiated as IUFD and PROM are followed by labour in many cases, and it is known that induction of labour is more likely to be successful if physiological mechanisms are invovled. IUFD may be considered a predictive factor in induction of labour as foetal indications for surgery like foetal distress are eliminated and induction duration can be prolonged. ${ }^{[13]}$ 
In our study, majority of patients were induced with PGE2 gel. According to Warke HS et al. stated PGE2 was drug of Choice. ${ }^{[14]}$ The method of choice for induction of labor has varied in different studies, WHO has recommended the use of prostaglandins for induction and among PG's, tab "Misoprostol" being cheap and not requiring special storage conditions has been studied in the unscarred uterus for induction in various trials. A total of 38 patients were induced using PGE2 gel, 9 patients via intracervical Foley's with gel, according to Rohan Chodankar et al intracervical Foley catheters are acceptable agents that are safe both in VBAC and in the outpatient setting. ${ }^{[15]}$

In our study 7 patients were induced with Mifepristone-Misoprostol whereas 5 patients delivered with Mifepristone only. According to Allen et al, misoprostol can be considered a safe and effective agent for labour induction in women with intact membranes, and on an inpatient basis. [16] Hapangama D et al, in their study of "Mifepristone for induction of labour" compared to placebo (108 women), mifepristone treated women were more likely to have a favourable cervix at 48 hours. ${ }^{[17]}$

The incidence of vaginal delivery was $94 \%$ and, LSCS section was $6 \%$. Based on the findings of this study, vaginal delivery, given its particular nature and physical, psychological, and social advantages, is highly valued by most people. In some previous studies, participants believed that vaginal delivery was necessary for the baby's lung development, improvement of mother-child emotional relationship, reduction of medication usage and other interventions such as epidurals and labor induction, and eliminating adverse labor-related outcomes; generally, they believed that vaginal delivery was less risky than $\mathrm{c}-$-section. [18]

In our series of patients, the LSCS rate was only $6 \%$ in the patients who were induced for various indications during the study. Various studies have raised the question of increasing rates of lower segment caesarean section (LSCS) and fears about the rates rising even further due to elective induction of labor at 41 weeks or more have been raised. These appear to be laid to rest by several authors, and some studies have found an overall reduction in LSCS rates by up to $20 \%$. The indications for which LSCS was performed were foetal distress, abnormal labour patterns, arrest or protracted descent and hyperactivity. ${ }^{[19]}$

In our study, Atonic Postpartum haemorrhage (PPH) $4 \%$ and Traumatic PPH was 2\%. These findings are correlate with the study done by Tasneem $\mathrm{F}$ et al. [20] Postpartum haemorrhage is a leading cause of maternal mortality. Atonic Postpartum haemorrhage is common among high risk pregnancies. Training of Medical staff in diagnosis of atonic PPH and differentiating between atonic and traumatic PPH is essential before introduction of UBT. Avoidance of any delay helps in reducing the blood loss. Intelligent anticipation regarding PPH, while delivering high risk woman helps in immediate interventions. PPH treatment includes four elements, communication, resuscitation, monitoring investigation and arresting the bleeding which must be taken simultaneously. Main therapeutic goals of management of massive haemorrhage is to maintain haemoglobin $>8 \mathrm{gm} / \mathrm{dl}$, platelet count $>75 \mathrm{x}$ 109/1, prothrombin $1.0 \mathrm{gm} / 1.1$. $^{[21]}$

\section{CONCLUSION}

In summary, our findings suggest that vaginal delivery is likely following preterm induction of labor irrespective of gestational age and low bishop score. Parity and cervical favourability are the first and second strongest predictors of a successful vaginal delivery, respectively. Labor curves accelerate with each category of gestational age, ultimately approximating those observed following term induction of labor. Induction of labor should be considered in women requiring preterm delivery and considerations should be made for gestational age in assessing labor progress.

\section{REFERENCES}

[1]. Rydahl E, Eriksen L, Juhl M. Effects of induction of labor prior to post-term in low-risk pregnancies: a systematic review. JBI Database System Rev Implement Rep. 2019;17(2):170-208.

[2]. WHO Recommendations for Induction of Labour. Geneva: World Health Organization; 2011. 1, BACKGROUND. Available from: https://www.ncbi.nlm.nih.gov/books/NBK131965/

[3]. Spong CY, Mercer BM, D'alton M, Kilpatrick S, Blackwell S, Saade G. Timing of indicated latepreterm and early-term birth. Obstet Gynecol. 2011;118

[4]. Mozurkewich EL, Chilimigras JL, Berman DR, et al. Methods of induction of labour: a systematic review. BMC Pregnancy Childbirth. 2011;11:84.

[5]. Sanchez-Ramos L, Kaunitz AM, Wears RL, Delke I, Gaudier FL. Misoprostol for cervical ripening and labour induction: a meta analysis. Obstet Gynecol. 1997;89:633-642.

[6]. Wing DA, Jones MM, Rahall A, Goodwin TM, Paul RH. A comparison of misoprostol and prostaglandin E2 gel for preinduction cervical ripening and labor induction. Am J Obstet Gynecol. 1995;172(6):18041810.

[7]. Rayburn WF. Prostaglandin E2 gel for cervical ripening and induction of labor: a critical analysis. Am J Obstet Gynecol. 1989;160(3):529-534.

[8]. Londero, A.P., Rossetti, E., Pittini, C. et al. Maternal age and the risk of adverse pregnancy outcomes: a retrospective cohort study. BMC Pregnancy Childbirth 19, 261 (2019).

[9]. Nichols MR, Roux GM, Harris NR. Primigravid and multigravid women: prenatal perspectives. J Perinat Educ. 2007;16(2):21-32.

[10]. Erickson M. E. Predictors of maternal-fetal attachment: An integrative review. 1996. Worldviews on Evidence-Based Nursing, e3(1), 56-72. 
[11]. Unger, H., Thriemer, K., Ley, B. et al. The assessment of gestational age: a comparison of different methods from a malaria pregnancy cohort in sub-Saharan Africa. BMC Pregnancy Childbirth 19, 12 (2019).

[12]. MaryJ. Berry, Tim Foster, Kate Rowe, Oliver Roberts on, Bridget Robson, Nevil Pier. Pediatrics Nov 2018, 142 (5)

[13]. Oyebode TA, Toma BO, Shambe IH, Kahansim MI, Embu HY, Daru PH, Sagay AS. Induction of labour at Jos University teaching, hospital, Jos, Nigeria: a four year review. Int J Res Med Sci 2015;3(8):1942-8.

[14]. Warke HS, Saraogi RM, Sanjwalla SM. Prostaglandin E2 gel in ripening of cervix in induction of labour. $\mathbf{J}$ Postgrad Med 1999;45:105.

[15]. Chodankar R, Sood A, Gupta J. An overview of the past, current and future trends for cervical ripening in induction of labour. The Obstetrician \& Gynaecologist 2017;19:219-26.

[16]. Allen R, O'Brien BM. Uses of misoprostol in obstetrics and gynecology. Rev Obstet Gynecol. 2009;2(3):159-168.

[17]. Hapangama D, Neilson JP. Mifepristone for induction of labour. Cochrane Database Syst Rev. 2009;2009(3):CD002865.

[18]. Zakerihamidi M, Latifnejad Roudsari R, Merghati Khoei E. Vaginal Delivery vs. Cesarean Section: A Focused Ethnographic Study of Women's Perceptions in The North of Iran. Int J Community Based Nurs Midwifery. 2015;3(1):39-50.

[19]. Gupta P, Jahan I, Jograjiya GR. Is vaginal delivery safe after previous lower segment caesarean section in developing country?. Niger Med J. 2014;55(3):260265.

[20]. Tasneem F, Sirsam S, Shanbhag V. Clinical study of post partum haemorrhage from a teaching hospital in Maharashtra, India. Int $\mathbf{J}$ Reprod Contracept Obstet Gynecol. 2017;6:2366-9.

[21]. Rani PR, Begum J. Recent Advances in the Management of Major Postpartum Haemorrhage A Review. J Clin Diagnos Resea. 2017 Feb;11(2):QE01QE05 